\title{
PLANO DE SUCESSÃO: UM ESTUDO DE CASO EM UMA EMPRESA FAMILIAR DE MÍDIA EXTERIOR ${ }^{1}$
}

\author{
SUCCESSION PLAN: A CASE STUDY IN AN FAMILY-OWNED OUTDOOR \\ MEDIA
}

\author{
Inayara Valéria Defreitas Pedroso Gonzalez ${ }^{2}$ \\ Ana Carolina Leiko Sato ${ }^{3}$ \\ Anderson Soncini Pelissari ${ }^{4}$ \\ Bethania Garcia Cid e Silva ${ }^{5}$
}

RESUMO: Objetivou-se com este estudo, compreender e descrever como se desenvolve um plano de sucessão familiar para uma empresa de mídia exterior que se encontra na sua primeira geração. Para isto, foi realizado um estudo de caso na empresa Color Painéis em Londrina-PR, bem como, a revisão bibliográfica acerca das características e conceitos ligados ao âmbito das empresas familiares quanto ao processo sucessório e os planos de sucessão. Esta pesquisa qualitativa, com natureza descritiva e exploratória se deu a partir da inexistência de estudos relacionados ao tema nesse tipo de negócio, além da necessidade de um_plano de sucessão por parte do fundador da empresa. Por meio do referencial teórico e da investigação empírica acerca do perfil de liderança, nível de criatividade e gestão de conflitos característicos nas empresas familiares, chegou-se a conclusão de que o fundador deve dedicar atenção às diferenças individuais dos candidatos à sucessão quanto ao comportamento de liderança, dedicação e investimento de cada um no desenvolvimento de idéias e ações inovadoras. Os resultados da pesquisa revelam que o plano de sucessão que melhor se adéqua às características da empresa analisada, é o do autor Oliveira (2006), visto suas etapas claras, em especial, as análises acerca do tratamento de possíveis conflitos característicos das empresas familiares, e a possibilidade de se escolher o perfil do sucessor conforme a missão, visão, valores e objetivos da empresa.

PALAVRAS-CHAVE: Empresa familiar; sucessão familiar; planos de sucessão; planejamento.

ABSTRACT: The objective of this study is to understand and describe how to develop a succession family plan for an abroad media company that finds itself in its first generation. For this, it was performed a case study in the company Color Paineis in Londrina-PR, as well as the literature about the characteristics and key concepts related to both family businesses, succession process and succession plans. This qualitative study, with descriptive and exploratory nature occurred from the lack of studies on succession in this type of business, and the need that the manager of the company has shown in developing a succession plan. Through theoretical and empirical research about the leadership profile, level of creativity and conflict management characteristic in family businesses, reached the conclusion that the founder should devote attention to individual differences of candidates for succession on the behavior of leadership, dedication and investment of each in the development of innovative ideas and actions. The search results show that the succession plan that best suits the requirements of the company is from author Oliveira (2006), since his clear steps, in particular, the analysis of the treatment of potential conflicts characteristic of family businesses, and possibility to choose the successor profile according to the mission, vision, values and goals of the company.

KEY WORDS: Business family; succession; succession plan; planning

\footnotetext{
${ }^{1}$ Artigo Recebido em 26.07.2010. Revisado por pares em 12.09.2011. Recomendado em 28.09.2011 por Leomar dos Santos Editor. Publicado em 10.02.2012.

Organização Responsável pelo periódico: Universidade regional de Blumenau - FURB - www.furb.br/rn
}

\footnotetext{
${ }^{2}$ Universidade Federal do Espírito Santo - UFES - gonzalezinayara@gmail.com

${ }^{3}$ Universidade Federal do Espírito Santo - UFES - aclsato1@hotmail.com

${ }^{4}$ Universidade Federal do Espírito Santo - UFES - asoncinipelissari@gmail.com

${ }^{5}$ Universidade Federal do Espírito Santo - UFES - bethaniagcid@hotmail.com
} 


\section{INTRODUÇÃO}

As empresas familiares ocupam grande parte da economia brasileira, representando um total de aproximadamente $75 \%$ dentre as empresas do país (OLIVEIRA, 2006). Além disso, representam mais de $90 \%$ da quantidade de empresas privadas no Brasil (GRZESZCZESZYN; MACHADO, 2006).

Juntamente com essa representatividade, Oliveira (2006) explica que as empresas do tipo familiar possuem certas particularidades que as diferenciam das demais, como, por exemplo, os valores e os laços entre seus membros, normalmente mais marcantes.

Essas características particulares da empresa familiar, quando somadas ao contexto em que o fundador busca planejar o processo de sucessão da gestão, podem ser variáveis determinantes durante a elaboração do seu plano de ação. A esse respeito, Passos et al. (2006) revelam que em determinada ocasião, o fundador terá que tomar uma difícil decisão ligada ao processo sucessório, que é a escolha do futuro sucessor.

Quanto a esse processo de sucessão, Leone (2005) e Oliveira (2006) argumentam que as empresas familiares são sucedidas de maneira hereditária. Complementando essa visão, Consoli e Martinelli (1998), Adachi (2006), Leone (2005) e Oliveira (2006) afirmam que muitos herdeiros podem acabar prejudicando a saúde da empresa, pois em diversos casos, há uma falta de comprometimento das gerações seguintes, as quais não possuem o mesmo tipo de dedicação pelo negócio como o fundador.

Essa dedicação diferenciada, quanto ao comprometimento dos filhos herdeiros em relação ao fundador, acaba gerando indícios de que pode haver pouco tempo de vida para as empresas do tipo familiar. Dados revelam que " $30 \%$ dessas empresas sobrevivem à segunda geração, e apenas 5\% passam para a terceira geração" (OLIVEIRA, 2006, p. 4). Isto, conforme Oliveira (2006) ocorre, por um lado, especialmente em virtude dos conflitos familiares, e a falta de planejamento no processo sucessório.

Por outro lado, esse mesmo autor (2006) trás a reflexão que as pessoas competentes não são eternas, mas as empresas bem administradas podem ser. Assim, quando se trata de empresas familiares, é importante que exista por parte do fundador, a preocupação quanto ao preparo do futuro gestor. Em outras palavras, que haja o planejamento da sucessão na busca pela longevidade da empresa.

Corroborando com essa lógica, Floriani e Rodrigues (2000) informam que além da maioria das empresas familiares não possuir um plano de sucessão familiar, há um despreparo generalizado para a sucessão, tanto por parte daquele que fundou o negócio, quanto daqueles que trabalham na empresa. Neste contexto de sucessão, em que deve haver a elaboração cuidadosa por parte do fundador, quanto a um plano de ação, é muito importante que haja um planejamento cuidadoso quanto ao perfil do futuro gestor (OLIVEIRA, 2006; ANTONIALLI, 1998).

Entende-se por processo de sucessão familiar: a primeira geração, o nascimento do negócio com seu fundador; segunda geração, o herdeiro ou não herdeiro, e assim sucessivamente durante as outras gerações (OLIVEIRA, 2006). Ambas as sucessões são práticas comuns, respectivamente, quando ocorre por parte de um herdeiro da família, e 
sucessão profissional, quando uma pessoa que não está relacionada diretamente com a família passa a gerenciar a empresa no lugar do fundador (OLIVEIRA, 2006).

Sendo o processo de sucessão um momento inevitável no âmbito interno da empresa, imbuído de alto risco pelo fator da mudança entre gerações, ele deve ser tratado de forma planejada (CAMPOS; MAZILLI, 1998; ANTONIALLI, 1998; e OLIVEIRA, 2006), sendo necessário compreender além da interação entre os membros da família, também o processo de crescimento e desenvolvimento da empresa e os papéis dos familiares que muitas vezes sobrepõem-se à lógica objetiva da estrutura da empresa (DONALDSON, 1999).

Campos e Mazilli (1998), Antonialli (1998) e Oliveira (2006) lembram ainda, que conflitos familiares podem ser eliminados, à medida que o fundador se preocupa em iniciar o processo de sucessão mais cedo; o que evita inclusive, possível falência (ANTONIALLI, 1998).

Diante dessas características relevantes, relacionadas ao plano e ao contexto de sucessão familiar, o presente estudo de caso busca responder a seguinte questão-problema:

Como desenvolver um plano de sucessão familiar para uma empresa de mídia exterior que se encontra na sua primeira geração?

O interesse em buscar estudar uma empresa de mídia exterior, ocorreu a partir da inexistência de estudos sobre plano de sucessão neste tipo negócio. Além disso, da acessibilidade aos dados e da necessidade que o gestor fundador da empresa demonstrou em desenvolver um plano de sucessão, com planejamento.

A discussão a respeito dos planos de sucessão em empresas familiares, cada vez mais, é foco de investigação. Exemplo disso é o caso do grupo Pão de Açúcar, que descreve como foram realizadas as sucessões ao longo dos anos, o qual envolveu tanto sucessão familiar quanto profissional (COSTA; LUZ, 2003). De acordo com Passos et al. (2006), tais estudos são realizados devido aos frequentes problemas enfrentados por essas empresas em relação aos conflitos familiares e ao planejamento do processo sucessório.

A busca por uma solução eficaz para estes problemas é necessária, e estudos que tentem desvendar as características de empresas familiares são de extrema importância para se poder chegar a um plano de sucessão eficaz ao longo dos anos, visto que, conforme Jesus, Machado e Jesus (2009), a mortalidade dessas empresas ainda é elevada.

A partir do conhecimento anterior sobre os fatores críticos relacionados ao momento de sucessão, e também, das características da empresa, perfís de liderança dos candidatos a sucessão e, do tipo de cultura existente, cria-se a possibilidade de elaboração planejada e coordenada de um plano de sucessão para a empresa que ainda se encontra na sua primeira geração. Assim, a investigação desta pesquisa seguiu algumas das características descritas por Freire et al. (2009) sobre as empresas familiares, a saber: identificação da missão dada e da missão cumprida; laços afetivos entre fundador, filhos e funcionários; os conflitos manifestos e, o investimento da família na empresa. Também foram investigados documentos sobre a visão e os valores da empresa, e realizadas entrevistas para aproximar os pesquisadores à cultura mantida pelo fundador, afinal, concordando com Goffee (1996), o exito do processo de sucessão incide também na habilidade do fundador em criar e comunicar uma cultura empresarial. Por meio de questionário, junto aos candidatos a sucessão, buscou-se identificar 
as perspectivas futuras vislumbradas para a empresa, facilitando assim a compreensão sobre a eficácia do plano de sucessão. Os planos de sucessão da literatura, utilizados nessa pesquisa, foram escolhidos por discutirem todo esse contexto ligado a conflitos, valores, crenças e liderança.

As lacunas que o presente estudo de caso visa preencher são: a) a ausência de trabalhos acerca do desenvolvimento planejado de um plano de sucessão para empresa familiar que se encontra na sua primeira geração, visto que há uma grande concentração de pesquisas tratando o tema sucessão, mas focando as consequências da sucessão ou como ele ocorreu, e não o desenvolvimento planejado do plano; b) a relativa escassez de estudos ligados a empresa familiar que promovam uma discussão a respeito do alinhamento entre perfis de liderança dos candidatos herdeiros à sucessão aos valores legitimados pelo fundador e, aos valores considerados por esses candidatos estratégicos para o futuro da empresa.

O estudo está organizado da seguinte forma: após a parte introdutória da pesquisa, segue o capítulo 2 que aborda o referencial teórico analisado, onde são trazidas características comuns à empresa familiar, teorias de liderança, e os modelos de planos de sucessão; o capítulo 3 contendo os procedimentos metodológicos; em seguida, no capítulo 4 a análise do caso Color Painéis, a partir do recorte teórico estudado, e por fim, no capítulo 5, as considerações finais do estudo com sugestões para pesquisas futuras.

\section{REFERENCIAL TEÓRICO}

\subsection{EMPRESA FAMILIAR}

Leone (2005) explica que a empresa do tipo familiar envolve três vertentes: $1^{\mathrm{a}}$ ) nível da propriedade; $2^{\mathrm{a}}$ ) nível da gestão; e, $3^{\mathrm{a}}$ ) nível da sucessão. A primeira tem relação com o controle efetivo da empresa. A segunda diz respeito ao gerenciamento, a influência da família no funcionamento da empresa, compondo a diretoria, os membros da família. A terceira relaciona-se com a sucessão, que é ligada as futuras gerações.

Adachi (2006, p.18), por sua vez, compreende que a "empresa familiar é uma organização na qual uma ou poucas famílias, concentram o poder de decisão e participam da gestão", e afirma que a família empresarial possui as seguintes características: organização; uma ou poucas famílias; domínio, e também a concentração do poder. Freire et al. (2010) concordam que a dificuldade em delegar poder de decisão, é uma das características das empresas familiares, principalmente quando ainda é administrada pelo fundador que tem dificuldade em renunciar o controle do negócio.

\subsubsection{Características da Empresa do Tipo Familiar E A Importância Da Liderança E Da Criatividade Para A Tomada De Decisão}

Um dos pontos mais importantes destacados na literatura sobre empresa familiar e transferência de gestão, é o conhecimento das características do fundador e dos candidatos a sucessão. Empresas onde a fundador ocupa posição-chave encontram problemas de sucessão, 
tais como a não separação da gestão e da propriedade (LEONE, 2005), além da dificuldade de seguir os passos do fundador, os seus valores e suas crenças. Assim, estudar as características dos candidatos a sucessão, torna-se chave para o entendimento do melhor perfil a conquistar o lugar do fundador.

Durante o processo de escolha do sucessor, há sempre a preocupação em avaliar seu comportamento e seus objetivos em relação aos da empresa. A qualidade das decisões dos gestores é ponto importante na escolha do sucessor. Essa qualidade na tomada de decisões, relaciona-se diretamente com a capacidade que os indivíduos demonstram na solução criativa dos problemas; sendo que a criatividade depende especialmente do processo e da competência dos envolvidos nas decisões (DACORSO et al., 2010). Da mesma forma que o conhecimento tácito, a criatividade pode ser definida como a habilidade de se fazer algo sem a capacidade de explicar por que foi feito daquela forma (DACORSO et al., 2010). Para Amabile, Hadley e Kramer (2002), a criatividade é uma variável que depende muito mais do esforço pessoal para ocorrer e das condições ambientais, do que da genialidade do indivíduo. Assim, o entendimento por parte do fundador, com relação ao perfil criativo e de liderança dos candidatos a sucessão na tomada de decisão, serve como facilitador na elaboração do melhor plano de sucessão.

Estudos sistemáticos sobre estilos de liderança datam de 1904 (FREITAS, 2006) e Kurt Lewin foi um estudioso do tema; quem revelou os estilos autocrático, democrático e liberal de liderança, respectivamente: - o líder que toma decisões sem consultar o grupo; o líder que compartilha com os funcionários suas responsabilidades de liderança e o líder que só intervem se for solicitado (FREITAS, 2006; MACHADO, 2000). O tema liderança, foi sempre de grande interesse em virtude da necessidade de se compreender traços comuns de personalidade dos líderes e da maneira como alcançam posições de chefia (FREITAS, 2006).

As primeiras abordagens para explicar liderança, sustentavam que os líderes não eram produzidos, mas nasciam líderes. Contudo, pesquisadores influenciados por escolas de pensamento comportamentais descartaram mais tarde essa idéia, sugerindo, ao contrário, que muitas características ligadas à liderança efetiva, podiam ser adquiridas (WAGNER III; HOLLENBECK, 2006).

Mais recentemente, pesquisadores começaram a propor várias teorias neo-universais de liderança centradas numa característica particular do líder, e que exclui, assim como os modelos universais anteriores, as análises voltadas aos seguidores e às situações. Entre essas teorias encontram-se as da liderança carismática que enfatiza a habilidade do líder de comunicar aos seguidores novas visões de organização (WAGNER III; HOLLENBECK, 2006).

A teoria da liderança situacional se mostra a mais abrangente que a teoria dos traços e as teorias comportamentais de liderança, pois dá ênfase ao dinamismo que cerca o processo de liderança decorrente da mudança da postura do líder, dos liderados e da situação. Conforme Hersey e Blanchard (1986), essa teoria assume a premissa de que não há um único estilo de liderança apropriado para toda e qualquer situação. Assim, o líder, os liderados e a situação, são assumidos como variáveis norteadoras do processo de liderança, tendo-se quando na 
liderança situacional, ênfase no comportamento do líder em relação aos liderados (HERSEY; BLANCHARD, 1986).

Contudo, novas abordagens centradas na competência do líder, estão sendo valorizadas. Quinn et al. (2003) já afirmavam que é preciso ter a capacidade de análise acerca dos ambientes internos e externos à organização, acompanhando as mudanças.

Para Passos et al. (2006), um ponto característico, relevante no âmbito das empresas familiares, é a interação entre as esferas desse sistema que é formado por três subsistemas: a família, o patrimônio e a empresa. A investigação do relacionamento entre essas esferas, é para os autores, passo fundamental no caminho a ser percorrido pela família empresária, e, portanto, no próprio plano de sucessão e sua continuidade. Nesse sentido, a análise acerca dos diferentes papéis do gestor, torna-se relevante. Davis e Newstrom (1992) explicam que a forma pela qual um líder usa o poder, também estabelece um tipo de estilo. Cada estilo autocrático, participativo e de rédeas livres, tem suas vantagens e limitações. Esses autores, afirmam que um líder usa todos os três tipos de estilos durante um período de tempo, mas um deles tende a ser o dominante. Uma ilustração dada por eles é a de um supervisor de fábrica, que normalmente é autocrático, mas é participativo na determinação da programação de férias e pode assumir o estilo de rédeas soltas ao selecionar o representante do setor para o comitê de prevenção de acidentes.

Passos et al. (2006) defendem que na família deve-se lembrar que os herdeiros serão sócios da empresa e do patrimônio, com isto, não se pode descuidar de cada fase do planejamento ao longo da sucessão. Por essa razão, a liderança é um tema chave, pois a determinação do melhor sucessor e do consequente modo de desenvolver um plano de sucessão, pode assegurar a longevidade da empresa. A interação dos três subsistemas (a família, o patrimônio e a empresa) visa à continuidade do negócio e o responsável por essa interação deve ser possuidor de competências relacionadas à liderança.

Somam-se a este contexto, a preocupação quanto aos conflitos entre os envolvidos no processo de gestão. Como se trata de uma variável que pode gerar impactos negativos durante a elaboração do plano, a seguir são apresentados alguns conflitos comuns às empresas familiares, conforme investigação bibliográfica.

\subsubsection{OS CONFLITOS NA EMPRESA DO TIPO FAMILIAR}

É mais comum conflitos em empresas familiares que em outras, em virtude da proximidade dos envolvidos e, da consequente forma de comunicação na resolução dos problemas que vão surgindo (ADACHI, 2006). Os conflitos podem surgir de pequenas atitudes que poderiam ser resolvidas de uma maneira simples, evitando-se o surgimento de um grande problema. Adachi (2006) cita alguns exemplos de combates ocorridos dentro das empresas familiares que foram manifestados por pequenos motivos:

Utilização de um funcionário da empresa para um conserto na residência de um parente; uso das instalações da empresa para uma atividade particular, ou pagamento feito pela empresa da assinatura de uma revista para a esposa de um dos sócios (ADACHI, 2006, p 210). 
A respeito de ações que geram possíveis conflitos, Passos et al. (2006) citam as intrigas entre irmãos durante uma reunião de tomada de decisão; um parente que começa a "falar mal" de outro, diante dos demais funcionários da empresa; fofocas e boatos e, disputas acirradas entre familiares, todos exemplos de conflitos nas empresas familiares. Dessa forma, vê-se que para uma empresa familiar sobreviver, é preciso conseguir administrar as relações e solucionar todos esses conflitos (LEONE, 2005). O fracasso das empresas familiares, para Leone (2005), advém das intrigas entre herdeiros, pois os familiares concorrem entre si à ascensão hierárquica e ao ganho do poder.

Diante deste contexto, observa-se que a estabilidade, o rigor disciplinar e a confiança entre os envolvidos no negócio familiar, são importantes para a longevidade do negócio. Para que esse comportamento aconteça, possibilitando o exercício do poder, é imprescindível que a estrutura formal apresente hierarquia, especialização, definição de competência, normas de conduta, documentação e arquivo, ingredientes formais da organização (WEBER, 1966).

Assim, diante de conflitos entre familiares, a importância do gerenciamento passa a ser fundamental para que todos os problemas possam ser minimizados e solucionados. Sendo assim, o entendimento das diferenças entre os indivíduos como forma de crescimento, é o primeiro passo para o gerenciamento (MONTANA; CHARNOV, 2006).

A investigação, quanto à maneira de tomar decisões, possibilita a compreensão de diferenças individuais, em que soluções ótimas exigem que a decisão alcançada seja melhor que todas as outras alternativas possíveis (WAGNER III, 2002). O conflito de idéias é relevante para as empresas, pois possibilita que diferentes percepções sejam geradas e aproveitadas da melhor maneira (MONTANA; CHARNOV, 2006), a partir da reflexão e análise das situações. O importante é que ações sejam tomadas por parte do fundador e/ou gestor do negócio, em especial quanto à criação de um plano para a sucessão (LEONE, 2005).

Por um lado, o sucessor deve se preparar para o cargo, e por outro, o fundador deve tornar esse processo mais claro, informando aos familiares detalhes de como está o encaminhamento para escolha do sucessor (LEONE, 2005).

\subsection{PROCESSO SUCESSÓRIO}

O processo sucessório representa um dos momentos mais importantes na busca por garantir a continuidade da empresa, e não se trata de um processo rápido (OLIVEIRA, 2006), além de ser uma fase, em que é preciso se ter grande cuidado, para que a sobrevivência da empresa não seja comprometida (COSTA; LUZ, 2003). Dentre os tipos de sucessão, é possível encontrar na literatura formas variadas de tratamento; por exemplo, os nove tipos de sucessão de GERSICK et al.(1997) ao longo do ciclo de vida da empresa familiar. Contudo, como abordado na introdução desta pesquisa, são três os planos de sucessão considerados neste estudo. As razões para este foco se devem ao fato de que tais planos, discutem a questão da liderança dos candidatos a sucessão, os valores mantidos pelo fundador, o gerenciamento de conflitos, os perfis de liderança, e porque abordam a sucessão na primeira geração, considerando-se que a forma de sucessão pode variar de acordo com as características de cada empresa. 


\subsubsection{TIPOS DE SUCESSÃO}

Tanto Oliveira (2006) quanto Leone (2005) expressam dois tipos de processos sucessórios: um relacionado à própria sucessão familiar, e outro relacionado à sucessão do tipo profissional. Enquanto o primeiro processo espelha uma geração mudando para outra, um membro da família ocupando o cargo deixado pela geração passada, no segundo, o gestor fundador tem maior facilidade de recrutamento e seleção, o que é uma boa opção, visto que um executivo profissional não membro da família pode, por exemplo, elevar o nível de conhecimento nas empresas familiares (OLIVEIRA, 2006; LEONE, 2005).

Oliveira (2006) argumenta que a sucessão do tipo familiar leva em consideração os valores, as atitudes e crenças dos membros influentes da família, sendo que para Leone (2005) a continuidade do comando familiar, é uma vantagem desse tipo de sucessão. Leone (2005) destaca a importância de existir a confiança necessária dentro do ambiente profissional e familiar, para que o processo de sucessão seja facilitado, para que não ocorra sob conflitos.

A Administração de conflitos é ponto de atenção durante toda a elaboração do plano de sucessão. Assim, a partir da investigação da literatura a respeito das diferentes abordagens sobre preparação, desenvolvimento e aplicação de um plano de sucessão, foram selecionados três modelos que se diferem e se complementam, e que posteriormente foram tratados conforme os conflitos presentes na empresa Color Painéis, foco desse estudo.

\subsection{PLANOS DE SUCESSÃO}

Para que o objetivo geral deste estudo de caso pudesse ser alcançado, ou seja, compreender e descrever como desenvolver um plano de sucessão familiar para uma empresa que se encontra na sua primeira geração, foi necessário o estudo detalhado de diferentes planos encontrados na literatura. A partir da comparação investigativa e num segundo momento simultânea, do que estava sendo visto na teoria e do que estava sendo coletado na prática a partir das leituras sobre o tema, três planos de sucessão foram selecionados para a realização do confronto entre teoria e prática, visto que, ou abordam questões ligadas a liderança (ANTONIALLI, 1998; PASSOS et al., 2006), ou da relevância de se trabalhar os valores na organização, tratando a cultura organizacional baseada em melhoria e aprendizado (OLIVEIRA, 2006), questões consideradas determinantes para o desenvolvimento de um plano de sucessão.

\subsubsection{Plano de Antonialli}

No plano de sucessão do autor Antonialli (1998), observou-se a preocupação com o desenvolvimento da liderança e a realização de treinamentos acadêmicos para ampliar a formação intelectual do futuro sucessor. Além disso, a descrição dos passos básicos para esse futuro gestor envolvendo inclusive uma série de ações preventivas com o objetivo de minimizar possíveis conflitos ligados ao processo sucessório nas empresas familiares.

Antonialli (1998) destaca em sua obra a preocupação que o fundador deve ter com o preparo do sucedido, evidenciando os seguintes quesitos: - Desenvolver alternativas de 

EXTERIOR

negócios fora da empresa para desenvolver herdeiros; e - Desenvolver alternativas e estilo de vida fora da empresa. Para o autor, o preparo do sucessor relaciona-se com as experiências em outras empresas, e com o desenvolvimento das habilidades necessárias, e do conhecimento acerca de cada setor, área ou processo do negócio.

Antonialli (1998) destaca que esse preparo envolve a prática de reuniões formais com todos os membros atuantes da família para a discussão de problemas, incluindo: reuniões sobre a sucessão; a transmissão das decisões realizadas para todos os membros da família; o estabelecimento de um programa de relacionamento para ser seguido pelos membros, evitando conflitos. Há também o preparo da empresa, que para Antonialli (1998) envolve: Tornar-se profissional; - Haver a separação gradual entre os familiares, propriedade e administração ou mudanças societárias; - Preparar os funcionários e a família para as modificações advindas do processo de sucessão; - Conhecer os centros de poder; Administrar as resistências; - Escolher o estágio consolidado da empresa para começar a sucessão; - Conhecer os funcionários com potencial para ter chances de crescimento na empresa; - Transmitir aos funcionários-chave sobre o acontecimento da sucessão, e se preciso, formular um plano de incentivo para mantê-los na empresa familiar.

Assim, para que o planejamento de sucessão seja realizado da melhor forma possível, é necessário que haja envolvimento de todas as partes: sucedido, sucessor, família e empresa, para que todos possam contribuir neste processo (ANTONIALLI, 1998).

\subsubsection{Plano de Sucessão na Visão dos autores Passos et al.}

Passos et al. (2006) propõem a espiral da sucessão e da continuidade por ser uma forma de planejar a sucessão sem uma ordem preestabelecida; ou seja, não há um momento predeterminado para começar, tampouco terminar. Esta espiral incorpora momentos distintos, com diversos processos, diferentes ferramentas e estruturas nas três esferas: família, patrimônio e empresa.

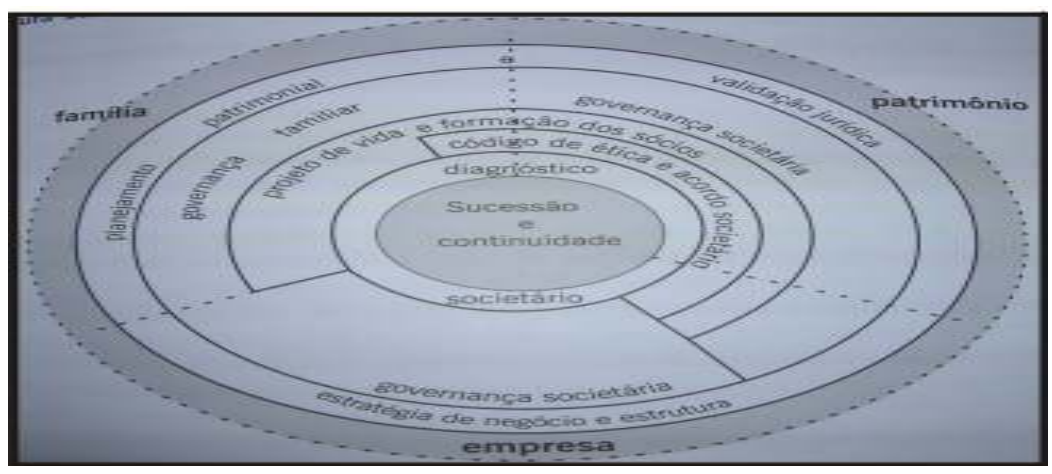

Figura 1: Espiral da Sucessão e Continuidade Fonte: Passos et al. (2006).

Passos et al. (2006) entendem que o primeiro passo que a família deve dar é realizar o diagnóstico societário. Esse diagnóstico é realizado nas três esferas: familiar, empresarial e 
patrimonial, permitindo aos familiares obter conhecimento quanto a sua história e, consequentemente, quanto a atual situação da empresa e do seu futuro.

Após o diagnóstico societário, os familiares terão que discutir o acordo societário para que os direitos e os deveres sejam regulados, e para que haja maior compromisso por parte dos membros da empresa. O acordo societário deve inclusive ser revisto periodicamente e construído através da participação e consenso de todos os familiares, pois está ligado tanto à família quanto à empresa, e principalmente ao patrimônio. Além disso, o código de ética passa a ser importante para o acordo societário, pois é nele que estão os princípios que envolvem a empresa familiar (PASSOS et al., 2006).

Os autores (2006) expõem que as discussões sobre o acordo societário e o código de ética originam a chamada estrutura de governança (familiar, corporativa e societária). Ao mesmo tempo, o projeto de vida de cada membro da família é trabalhado, independente da geração que se enquadra, através dos esforços da empresa familiar.

Pelo fato da espiral estar relacionada com as três esferas, será necessário ter um líder para cada uma delas (PASSOS et al., 2006). A liderança familiar deve ser representada por um membro da família, e assim estar legitimada para exercer esta função. O líder deverá ouvir mais do que dialogar, pois ele terá que compor os interesses de todos os membros pertencentes à empresa familiar, além de manter a valorização do legado da família. Simultaneamente, o líder deve compreender ambientes em constante mudança e sabe agir no melhor tempo possível, sempre mobilizando as pessoas para o fim desejado.

$\mathrm{Na}$ liderança patrimonial, o líder deve ter condições de articular as pessoas e os familiares, sendo necessário possuir a aceitação de todos os sócios familiares e estar propenso a não se expor demais em relação ao mercado. Além disso, estar sempre atento às esferas família e empresa, para assim buscar o melhor retorno de capital, sempre considerando todos os riscos envolvidos (PASSOS et al., 2006).

Por fim, a espiral da sucessão e continuidade forma fóruns específicos para essa estrutura de governança, sendo que a empresa familiar deve buscar renovação e revigoração das estratégias através do planejamento estratégico adequado à empresa (PASSOS et al. 2006).

\subsubsection{Plano de Sucessão do autor Oliveira}

O plano de sucessão de Oliveira (2006) é composto por cinco fases, sempre com o objetivo de chegar ao futuro sucessor. Na FASE 1 do seu plano, o autor (2006) menciona a identificação dos resultados a serem alcançados. Nesse momento deve ser feita a identificação dos componentes da organização que se pretende alcançar no futuro, como: a missão, a visão, os valores e os objetivos da empresa.

Na FASE 2 deve ser estabelecido o perfil básico do profissional, e ser elaborado um levantamento dos aspectos ligados ao conhecimento e habilidades do futuro sucessor. O perfil deve ser estabelecido, conforme explica o autor, de maneira interativa, com algumas forças para impulsionar a empresa familiar, por exemplo: a criatividade e a inovação, a vantagem tecnológica, a cultura organizacional baseada em melhoria e aprendizado, os processos bem 
sintonizados e geração otimizada de valor, a obsessão com a qualidade e, os trabalhos com equipes multidisciplinares.

Na FASE 3 é realizado um amplo debate dos resultados esperados e do perfil básico do executivo sucessor. Trata-se da fase para fechamento do processo, tendo em vista a perfeita interação dos resultados esperados, além do perfil básico desejado. Para Oliveira (2006), se essa fase for bem trabalhada, o processo de sucessão ocorrerá da forma desejada, alavancando os resultados da empresa familiar (OLIVEIRA, 2006).

Na FASE 4 é realizada a escolha do executivo sucessor, uma etapa que pode ser tanto fácil como difícil, dependendo do que ocorreu nas fases anteriores. Neste momento, a franqueza e a honestidade devem sustentar o processo para a análise final e para a escolha do executivo que sucederá a empresa. Por fim, na última parte do plano, FASE 5, ocorre a consolidação do processo sucessório, a implementação da sucessão. Sempre que possível, o executivo catalisador da sucessão deve concentrar um nível de esforço e de atenção para que sua evolução seja a mais adequada possível, apresentando os resultados esperados (OLIVEIRA, 2006).

Portanto, para que o planejamento do processo sucessório nas empresas familiares seja viável, é fundamental para Oliveira (2006), a interação dessas cinco fases, tendo-se total cuidado em cada uma delas para que se chegue à implementação e consolidação do plano.

\section{PROCEDIMENTOS METODOLÓGICOS}

Para que a questão-problema pudesse ser respondida, este estudo qualitativo, tipo estudo de caso, fez uso da técnica de levantamentos bibliográficos, envolvendo livros e artigos, buscando identificar e descrever as características essenciais a respeito do desenvolvimento de um plano de sucessão para uma empresa que se encontra na sua primeira geração. A presente pesquisa tem natureza exploratória e descritiva, visto sua preocupação com atuação prática, buscando compreender e descrever as características da empresa analisada (GIL, 2009), ou seja, o negócio familiar ligado à mídia exterior.

A Figura 2 revela o direcionamento metodológico do estudo: 


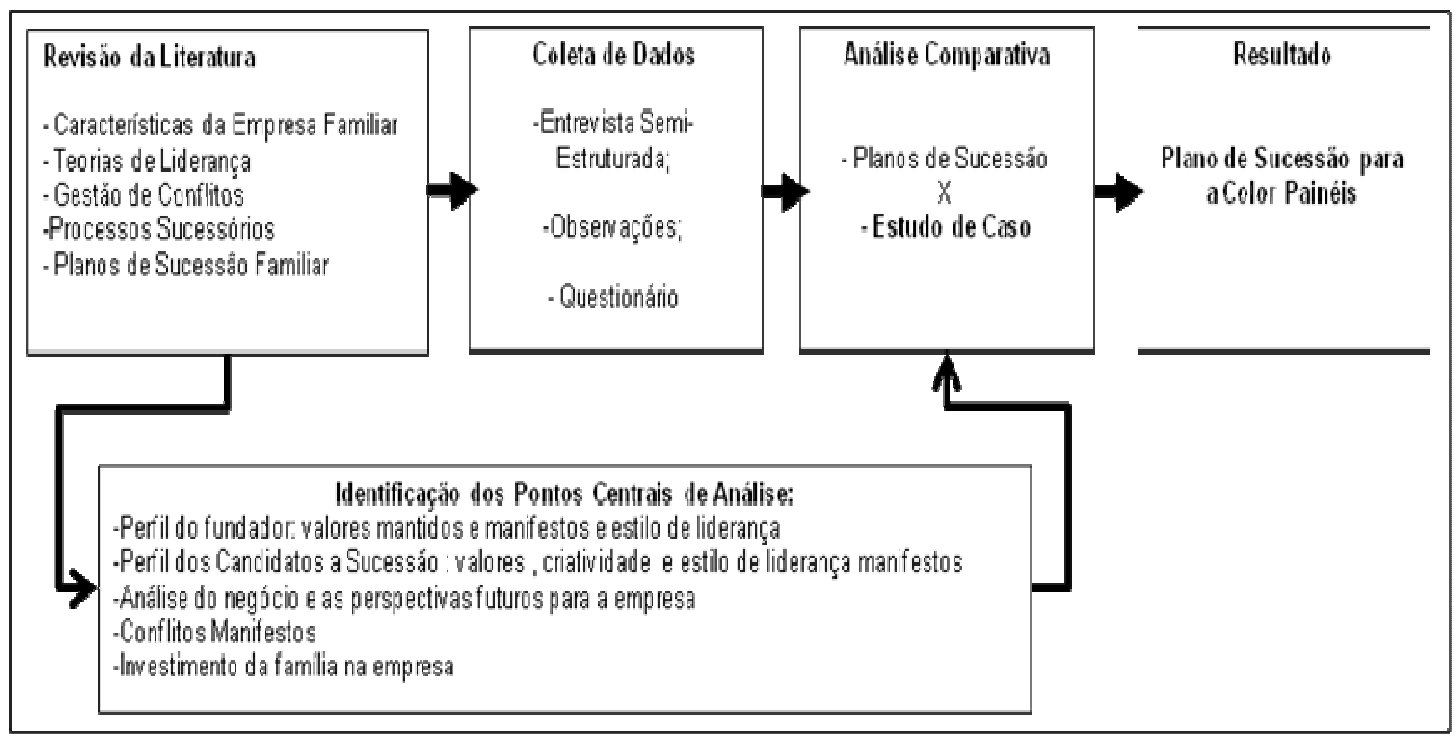

Figura 2: Método do Estudo.

Fonte: Elaborado pelos autores (2009).

\subsection{TIPOLOGIA E NATUREZA DO ESTUDO}

Optou-se pela pesquisa do tipo estudo de caso, pois houve a busca pela análise do objeto de forma profunda e intensa; ou seja, objetivou-se descrever, compreender e interpretar a complexidade de um caso definido (MARTINS, 2006), fazendo-se uso do protocolo de estudo de caso conforme orienta Yin (2001). Assim, elaborou-se a descrição da visão geral do estudo, com seus objetivos, interesse da pesquisa, autores relacionados ao tema, procedimentos de acesso aos dados em campo, aos locais do estudo de caso, e a especificação das informações bibliográficas. Além disso, sobre o acesso aos entrevistados chaves, os meios de se obter auxílio junto aos sujeitos da pesquisa quando não se tem a plena compreensão de certas informações, e o cronograma detalhado das fases do estudo.

Por se tratar de um estudo de caso, Martins (2006) afirma que esta tipologia pede avaliação qualitativa, que se caracteriza pela descrição, compreensão e interpretação de determinados fatos e fenômenos. A natureza descritiva é relevante neste estudo, pois descreve as características de uma determinada população (GIL, 2009), no caso, a empresa familiar de mídia exterior.

Visto a necessidade de se obter informações sobre o universo analisado, esse estudo também possui natureza exploratória, pois visa explorar o tema, proporcionando maiores informações e conhecimentos sobre o assunto estudado (ANDRADE, 2003).

\subsection{A EMPRESA COLOR PAÍNEIS E OS SUJEITOS DA PESQUISA}

A população investigada foi a empresa familiar brasileira denominada "Color Painéis", situada em Londrina, Estado do Paraná. A Color apresenta um total de 38 funcionários. Em janeiro de 1964, no período da fundação, a empresa iniciava suas atividades 
com a fabricação de luminosos e painéis de divulgação apenas com luz interna. Na década de 70, o fundador foi um dos primeiros a iniciar a atividade de instalação em painéis rodoviários no Paraná. No decorrer dos anos, com a necessidade de se desenvolver no mercado, a empresa começou a expandir buscando vários tipos de mídia exterior, tais como:

\begin{tabular}{|c|l|}
\hline Mídia Exterior & \multicolumn{1}{|c|}{ Descrição } \\
\hline Outdoor & Face exposta em locais de visibilidade privilegiada para exibição de propaganda. \\
\hline Front light & $\begin{array}{l}\text { Painel de varias dimensões iluminados com holofotes externos para a exibição da } \\
\text { propaganda em um determinado tempo. }\end{array}$ \\
\hline Top Sight & Painel de dimensões reduzidas a de front light. \\
\hline Triedro & Painel de diversos tamanhos iluminados com holofotes que se movimentam girando. \\
\hline $\begin{array}{c}\text { Painel } \\
\text { rodoviário }\end{array}$ & $\begin{array}{l}\text { Painel montado em chapa galvanizada, com a exibição das propagandas e instalado no } \\
\text { perímetro urbano ou rodovia. }\end{array}$ \\
\hline
\end{tabular}

Quadro 1: TIPOS DE MÍDIA EXTERIOR COMERCIALIZADOS PELA COLOR PAINÉIS

Fonte: dados da entrevista (2009)

Por ser pioneira neste ramo de atividade, a "Color Painéis" oferece mais de 120 locais de exibição de todas as suas mídias na cidade de Londrina e região. Conforme entrevista com o fundador da empresa:

(...) os painéis eram e continuam sendo montados em chapas galvanizadas com a exibição das propagandas, e instalados no perímetro urbano ou rodovia (...) os clientes dessa empresa de mídia exterior, são as empresas que buscam divulgar a imagem para conseguir o retorno financeiro esperado.

Além disso, o empresário fundador relatou estimar que a demanda mensal da empresa é de aproximadamente 55 clientes para a solicitação de locais de exibição de mídia exterior. Além desta demanda substancial pelo serviço, o filho mais novo do fundador relatou que o crescimento da empresa também é atribuído ao espírito empreendedor, à liderança, e à perseverança do fundador da empresa. Ambos, o fundador e seu filho mais novo, foram entrevistados e observados na fase piloto deste estudo de caso. Na fase definitiva, após a fase piloto, todos os outros sujeitos da pesquisa foram entrevistados e também observados.

\subsubsection{Sujeitos da Pesquisa}

O estudo na empresa Color englobou os Sujeitos (A-E) destacados no Quadro 2:

\begin{tabular}{|c|c|c|c|c|c|}
\hline Sujeito & Idade & Cidade & $\begin{array}{c}\text { Número } \\
\text { de filhos }\end{array}$ & Formação Profissional & Área de Atuação \\
\hline A & $\begin{array}{c}85 \\
\text { anos }\end{array}$ & Londrina & 4 filhos & Não possui & $\begin{array}{c}\text { Fundador e atuante da Color } \\
\text { Painéis }\end{array}$ \\
\hline B & $\begin{array}{c}56 \\
\text { anos }\end{array}$ & Londrina & 2 filhos & Não possui & Executivo da Color Painéis \\
\hline C & $\begin{array}{c}62 \\
\text { anos }\end{array}$ & Curitiba & 2 filhos & Não possui & $\begin{array}{c}\text { Gerente de uma agencia de } \\
\text { publicidade e propaganda }\end{array}$ \\
\hline D & $\begin{array}{c}58 \\
\text { anos }\end{array}$ & Curitiba & 3 filhos & Não possui & $\begin{array}{c}\text { Executivo de uma empresa de } \\
\text { mídia exterior }\end{array}$ \\
\hline E & 53 & Londrina & 1 filho & Biomédica & Ministra palestras e cursos \\
\hline
\end{tabular}




\begin{tabular}{|l|l|l|l|}
\hline anos & & técnicos \\
\hline
\end{tabular}

Quadro 2: CARACTERIZAÇÃO DOS SUJEITOS A a E.

Fonte: dados da pesquisa (2009)

Quando na fase piloto com os sujeitos A e B, houve o objetivo de verificar os limites de investigação para esta pesquisa, se seria possível obter as informações necessárias, conhecer a empresa e planejar a coleta dos dados da outra etapa de investigação. Além disso, verificar o comportamento dos Sujeitos A e B que são sócios. Obteve-se a informação de que o comando da empresa continua nas mãos do Sujeito A, embora o Sujeito B tenha bastante atribuição e poder nas tomadas de decisão. A parceria entre estes dois sujeitos exige responsabilidade, interação, e o respeito e a aceitação de opiniões, que são pontos cruciais para que a empresa tenha plena continuidade, conforme explicam os envolvidos.

Foi na primeira fase piloto de observações, que ficou evidenciado que a "Color Painéis" não possuía um planejamento do processo sucessório claro e definido, o que para Oliveira (2006) representa um risco de a empresa vir a falir. Isso foi o que motivou o interesse por desenvolver essa pesquisa, ou seja, compreender e descrever como desenvolver um plano de sucessão para essa empresa que se encontra na sua primeira geração.

\subsection{Instrumentos De Coleta De Dados}

As fontes primárias utilizadas na coleta de dados, durante a fase piloto de investigação foram as observações e entrevistas semi-estruturadas, em que as informações, dados e opiniões foram todos obtidos a partir de uma conversa livre, com pouca atenção a um roteiro de perguntas (MARTINS, 2006). Quanto às fontes secundárias, o estudo utiliza livros e artigos.

Os dados e informações coletados na fase piloto na empresa Color Painéis, foram utilizados para dar andamento e continuidade na elaboração deste estudo. $O$ objetivo foi identificar a relação entre os familiares, os conflitos enfrentados e o processo decisório tomado na empresa. Além disso, obter conhecimento sobre o histórico e suas características gerais. O período destas entrevistas e observações é descrito na Tabela 1:

Tabela 1: PERÍODO DE ENTREVISTAS E OBSERVAÇÕES REALIZADAS NA COLOR PAINÉIS (SUJEITOS A e B)

\begin{tabular}{c|l|l|l}
\hline \multicolumn{1}{c|}{ Dia do Mês } & \multicolumn{1}{c|}{ Dia da Semana } & \multicolumn{1}{c}{ Hora } & \multicolumn{1}{c}{ Entrevistado(s) } \\
\hline $20 / 08 / 2009$ & Quinta-feira & $10: 00-11: 30 \mathrm{hrs}$ & Sujeito A \\
\hline $21 / 08 / 2009$ & Sexta-feira & $9: 00-10: 00 \mathrm{hrs}$ & Sujeito B \\
\hline $24 / 08 / 2009$ & Segunda-feira & $14: 00-15: 30 \mathrm{hrs}$ & Sujeito A; Sujeito B \\
\hline
\end{tabular}

Fonte: dados da pesquisa (2009)

O fundador (Sujeito A) da Color Painéis explanou por aproximadamente uma hora sobre a história de sua empresa e a respectiva vivência, os produtos comercializados e serviços prestados, a quantidade de funcionários e a quantidade de herdeiros que atuam na 

EXTERIOR

empresa. Por fim, discorreu sobre os trabalhos realizados na Color Painéis e sua dedicação dentro dela.

No dia seguinte, houve uma entrevista com o Sujeito B, não havendo um roteiro de perguntas; em que ele ofereceu informações sobre sua trajetória dentro da empresa e sobre a relação com o pai e os irmãos, além do seu interesse em dar continuidade nos negócios da família.

No dia 24 de agosto de 2009, os Sujeitos A e B foram entrevistados ao mesmo tempo. Houve uma discussão sobre os objetivos e valores da empresa, a missão e visão, conflitos e, a relação do fundador com os seus descendentes, os planos futuros para a continuidade da empresa, o desejo de realizar um plano de sucessão, e das vantagens deste plano para os entrevistados.

Após a fase piloto de investigação, os Sujeitos C, D e E foram entrevistados via telefone e explanaram a respeito de três pontos: as relações com os irmãos e com o pai, o que estão realizando na vida profissional, e os interesses com relação à empresa Color Painéis. O período destas entrevistas e observações na empresa é apresentado na Tabela 2:

Tabela 2: PERÍODO DE ENTREVISTAS E OBSERVAÇÕeS REALIZADAS NA COLOR PAINÉIS (SUJEITOS C, D e E)

\begin{tabular}{r|l|l|l}
\hline \multicolumn{1}{c|}{ Dia do Mês } & \multicolumn{1}{|c|}{ Dia da Semana } & \multicolumn{1}{c}{ Hora } & \multicolumn{1}{c}{ Entrevistado/Observado } \\
\hline 09/09/2009 & Quarta-feira & $14: 00-14: 40 \mathrm{hrs}$ & Sujeito D \\
\hline $15 / 09 / 2009$ & Terça-feira & $14: 00-14: 45 \mathrm{hrs}$ & Sujeito C \\
\hline $17 / 09 / 2009$ & Quinta-feira & $10: 00-10: 30 \mathrm{hrs}$ & Sujeito E \\
\hline
\end{tabular}

Fonte: dados da pesquisa (2009)

Realizadas as entrevistas semi-estruturadas e as observações, foi aplicado um questionário de pesquisa aos Sujeitos "A" à "E". O questionário seguiu um roteiro de questões abertas e fechadas, envolvendo perguntas acerca dos comportamentos que mais se aproximam do gestor fundador e também dos candidatos a sucessão, tomando-se como base os pontos extraídos do referencial teórico e da investigação piloto. O questionário foi respondido via e-mail devido a uma maior comodidade proporcionada por este meio de comunicação, tendo-se como objetivo identificar o estilo de liderança, características como criatividade, assim como sobre o quê os impulsiona, as questões mais fundamentais para cada um, e o potencial de confiança gerado nos relacionamentos.

\subsection{Tratamento Dos Dados}

Este estudo de caso explorou o referencial teórico relacionado a diferentes planejamentos do processo de sucessão, e em seguida, evidenciou qual o plano que melhor se adéqua à empresa investigada, por meio da análise comparativa, conforme já abordado.

O método qualitativo não pretende fazer uso de categorias homogêneas ou numerar ou medir unidades (OLIVEIRA, 2002), mas objetiva conhecer a realidade segundo a perspectiva dos sujeitos participantes (TRIVIÑOS, 1987). 


\section{ANÁLISE DO CASO COLOR PAINÉIS}

Por meio das análises feitas, sobre o referencial teórico e dos dados extraídos na empresa Color Painéis, foram identificados pontos centrais de investigação e avaliação do fenômeno, foco desta pesquisa. A partir deste ponto, segue-se com a apresentação das análises desses pontos centrais (descritos no capítulo da metodologia) que serviram de base para a investigação quanto ao desenvolvimento de um plano de sucessão que melhor atende a empresa Color Painéis, na cidade de Londrina no Paraná, que se encontra na sua primeira geração.

\subsection{Tipo De Gestão}

A investigação quanto às características da gestão praticada na empresa Color Painéis, é essencial para a análise sobre como desenvolver o melhor plano de sucessão familiar, pois como já evidenciado, a maneira de tratar os conflitos comuns ao negócio, e de verificar as características dos ambientes interno e externo à empresa, é determinante para a longevidade da empresa. Nesse sentido, Antonialli (1998) valoriza a experiência do candidato a sucessão, fora da empresa, a fim de torná-lo capaz para o cargo de gestor do negócio familiar.

Conforme foi constatado por meio da pesquisa empírica, na gestão da Color Painéis existem estratégias definidas e planejamentos a respeito do futuro, assim como a definição de objetivos a serem seguidos e atingidos em um determinado prazo, que são discutidos entre os sócios. Dentre os principais objetivos da empresa, estão: a) melhoria da qualidade do produto; b) reforço do relacionamento com os colaboradores e fornecedores; c) ampliação do número de clientes para aumentar a margem de lucro; d) diminuição dos gastos extras; e) estar sempre atualizado quanto às novas tecnologias; f) buscar diferenciação dos produtos e serviços frente aos concorrentes; g) e manter e melhorar o nível de flexibilidade da empresa.

Diante de tais objetivos, observa-se que tanto o processo de sucessão de Antonialli (1998) quanto o do autor Oliveira (2006), alinham-se aos valores mantidos na Color Painéis, visto que o primeiro enfatiza a importância dos treinamentos e da experiência para a gestão bem sucedida, e o segundo aborda a cultura voltada para a melhoria e aprendizado.

O modo como são manifestadas as ações dos envolvidos no negócio, sobre todo esse planejamento, foi investigado a partir das técnicas de observação e entrevista junto aos envolvidos. Essa preocupação é relevante, na medida em que os valores pessoais puderam ser confrontados com os valores organizacionais, a fim de trazer à tona o tipo de cultura praticada na empresa. Essa identificação corrobora para a compreensão sobre como desenvolver o melhor plano de sucessão, na medida em que os valores do fundador e dos candidatos a sucessores, foram considerados.

Os valores do fundador foram identificados na missão e visão da empresa: "Promover e divulgar marcas de produtos e serviços em mídia exterior de forma íntegra e inovadora, tendo como base uma postura socialmente responsável e ambientalmente sensível" (DADOS DA PESQUISA, 2009). Como valores e visão, a empresa busca e visa: "Integridade, foco no cliente e compromisso com a segurança e a preservação do meio ambiente" (DADOS DA PESQUISA, 2009). Quanto à visão: 
"Ser a melhor empresa de mídia exterior na região de Londrina, buscando ter excelência no atendimento ao cliente e na logística de operações do serviço, além de um ambiente empresarial de harmonia e aprendizagem" (Sujeitos A e B).

Esses valores divulgados na empresa, formalmente pelo fundador, puderam ser avaliados comparando-os com a postura e com o perfil de liderança de cada um dos candidatos à sucessão. A forma como ocorre a interação desses valores, com o perfil de cada candidato a sucessor, pode tanto manter como alterar os valores do fundador. A atuação de cada um dos sucessores possibilitará ou não aos liderados (funcionários da empresa) o ambiente de aprendizagem e de harmonia que foram divulgados pelo fundador. Assim, essa avaliação foi considerada na elaboração do plano de sucessão, auxiliando na escolha do futuro gestor.

Quanto ao estilo de liderança dos sujeitos investigados, a partir do questionário de pesquisa baseado no referencial teórico e aplicado aos sujeitos envolvidos neste estudo, foi possível atribuir a cada um deles o estilo de liderança e também o nível de criatividade (Quadro 3) seguindo o entendimento dos autores Amabile, Hadley e Kramer (2002) quanto a criatividade.

\begin{tabular}{|c|l|l|}
\hline Sujeitos & \multicolumn{1}{|c|}{ Estilo de Liderança } & \multicolumn{1}{c|}{ Nível de Criatividade } \\
\hline A & Autocrático & 24 (Moderadamente criativo) \\
\hline B & Democrático & 33 (Muito criativo) \\
\hline C & Democrático & 22 (Pouco criativo) \\
\hline D & Democrático & 35 (Muito criativo) \\
\hline E & Democrático & 20 (Pouco criativo) \\
\hline
\end{tabular}

Quadro 3: ESTILO DE LIDERANÇA E NÍVEL DE CRIATIVIDADE DOS SUJEITOS A a E

Fonte: dados da pesquisa (2009)

O Sujeito A, através do acúmulo de conhecimento adquirido durante os anos de gestão da sua empresa, o utiliza no relacionamento com seus clientes, fornecedores, colaboradores, bem como seus herdeiros. Por meio dos instrumentos de coleta de dados, observou-se que o estilo de liderança exercido por ele, tende mais ao autocrático, pelo fato de frequentemente tomar as decisões referentes à empresa e comunicá-las aos colaboradores (FREITAS, 2006).

Em relação ao nível de criatividade, o sujeito A apresentou ser moderadamente criativo; ou seja, possui algumas idéias, porém com frequência não as coloca em prática.

Os Sujeitos B, C, D e E, mostraram ter um estilo de liderança democrático por tomarem as decisões considerando também a dos demais. As habilidades observadas durante as entrevistas semi-estruturadas e o confronto das percepções dos envolvidos acerca dos membros da família foram que, o:
a) Sujeito B: possui boa comunicação e sabe conviver em grupo;
b) Sujeito C: possui boa comunicação e tem competência ao realizar tarefas;
c) Sujeito D: possui poder de adaptação e habilidades técnicas;
d) Sujeito E: possui boa comunicação e habilidades técnicas.

Com relação ao nível de criatividade, houve uma diferença nos resultados, em que os Sujeitos B e D apresentam o nível de criatividade mais elevado, ou seja, são muito criativos, e 
conseguem expor inclusive, na prática, suas idéias. Já os Sujeitos C e E, de acordo com as respostas no questionário de pesquisa, são pouco criativos, sendo que suas ações ainda são facilmente influenciadas por outros.

Um ponto também questionado aos sujeitos $(\mathrm{A}, \mathrm{B}, \mathrm{C}, \mathrm{D}, \mathrm{E})$, foi com relação às forças que podem impulsionar uma empresa familiar ao longo do tempo, para um caminho de melhorias. No Quadro 4, são apresentadas as duas forças que foram consideradas como sendo de maior importância:

\begin{tabular}{|c|l|}
\hline Sujeitos & \multicolumn{1}{|c|}{ Forças Impulsionadoras } \\
\hline A & $\begin{array}{l}\text { 1) Obsessão com a qualidade; 2) Cultura organizacional baseada em melhoria contínua e } \\
\text { aprendizado. }\end{array}$ \\
\hline B & 1) Criatividade e Inovação; 2) Obsessão com a qualidade. \\
\hline C & $\begin{array}{l}\text { 1) Cultura organizacional baseada em melhoria contínua e aprendizado; 2) Obsessão com a } \\
\text { qualidade. }\end{array}$ \\
\hline D & $\begin{array}{l}\text { 1) Obsessão com a qualidade; 2) Cultura organizacional baseada em melhoria continua e } \\
\text { aprendizado. }\end{array}$ \\
\hline E & $\begin{array}{l}\text { 1) Obsessão com a qualidade; 2) Cultura organizacional baseada em melhoria continua e } \\
\text { aprendizado. }\end{array}$ \\
\hline
\end{tabular}

Quadro 4: FORÇAS CONSIDERADAS IMPORTANTES PELOS SUJEITOS

Fonte: dados da pesquisa (2009)

Ao verificar o Quadro 4, percebe-se que todos os sujeitos dão prioridade em pelo menos uma das forças que estão ligadas aos objetivos e missão, estabelecidos pela empresa. A força impulsionadora "obsessão com a qualidade" está diretamente ligada ao objetivo "melhorar a qualidade do produto". Quanto à "criatividade e inovação", encaixa-se na missão e nos objetivos da Color Painéis; e com relação à "cultura organizacional baseada em melhoria contínua e aprendizado", também se liga a alguns dos objetivos da empresa, como, por exemplo: estar sempre atualizado quanto às novas tecnologias.

Além das forças impulsionadoras, foi questionado aos sujeitos, quanto às questões prioritárias que os gestores de uma empresa familiar devem estar atentos. O Quadro 5 mostra a questão prioritária de cada sujeito.

\begin{tabular}{|c|l|}
\hline Sujeitos & \multicolumn{1}{c|}{ Questões Prioritárias } \\
\hline A & Melhoria constante do nível de flexibilidade da empresa, conseguindo adaptar-se às mudanças \\
\hline B & Diferenciação nos produtos e serviços oferecidos \\
\hline C & Seletividade e nicho de mercado \\
\hline D & Diferenciação nos produtos e serviços oferecidos \\
\hline E & Seletividade e nicho de mercado \\
\hline
\end{tabular}

Quadro 5: QUESTÃO PRIORITÁRIA DOS SUJEITOS DE A a E

Fonte: dados da pesquisa (2009)

Ao analisar as questões que são prioritárias para cada sujeito, percebe-se que alguns possuem pontos de vista diferentes. O Sujeito B e o Sujeito D consideram a diferenciação dos produtos e serviços oferecidos como uma prioridade, sendo esta questão mais direcionada aos objetivos que a Color Painéis apresenta. 
Outro ponto questionado aos sujeitos foi com relação à geração de confiança nos relacionamentos através dos comportamentos de cada um. O Quadro 6 retrata o potencial de geração de confiança de cada sujeito envolvido neste estudo.

\begin{tabular}{|c|l|}
\hline Sujeitos & \\
\hline A & Grau médio \\
\hline B & Grau médio \\
\hline C & Grau médio \\
\hline D & Grau médio \\
\hline E & Grau médio \\
\hline
\end{tabular}

Quadro 6: POTENCIAL DE GERACAO DE CONFIANÇA

Fonte: dados da pesquisa (2009)

O Quadro 6 mostra que todos os sujeitos possuem grau médio em relação ao potencial de geração de confiança. Isto mostra que os comportamentos referentes a cada um dos sujeitos não os levam a criar confiança em todas as pessoas que os cercam, mas sim, para algumas delas.

Após a verificação do nível de criatividade, estilos de liderança, forças impulsionadoras, questões prioritárias e geração de confiança nos relacionamentos de cada um dos sujeitos envolvidos nesta pesquisa, observou-se que: apesar do Sujeito A (fundador) ter um estilo que não coincide em alguns pontos com os outros sujeitos, isto não significa que o sucessor deva ter esse perfil, ao contrário, a alteração do perfil pode provocar melhorias interessantes à empresa.

Contudo, vale ressaltar que o perfil do sucessor deve estar em sintonia com a missão, visão, valores e objetivos da empresa. Assim, a partir das entrevistas semi-estruturadas, das observações realizadas e do questionário de pesquisa aplicado, foi possível perceber que o Sujeito A possui forte identificação com os valores e as crenças da família. Com isto, o tipo de gestão encontrada na Color Painéis, por parte do fundador, é a tradicional, movida por hábitos, pela tradição, onde predominam as características patriarcais e de patrimônio, apesar de existir como descrito a seguir, a consideração por parte do fundador quanto às opiniões dos herdeiros.

\subsection{Descrições do Ambiente Da Empresa: Acordos E Conflitos}

As investigações realizadas nos meses de agosto e setembro, mostraram alguns conflitos da empresa analisada a partir das percepções encontradas, por exemplo:

“(...) o fundador não quer se aposentar” (Sujeito B); “(...) há a falta de entrosamento entre os irmãos, gerando disputa pelo poder” (Sujeito A); “(...) há a falta de reuniões para discutir a sucessão, devido a presença do fundador” (Sujeito B).

No que diz respeito ao relacionamento entre os sujeitos envolvidos na Color Painéis, observou-se que a esposa do fundador, quando presente, o acompanhava em todos os compromissos, e o incentivava sempre que preciso. A dedicação da esposa em momentos difíceis foi o alicerce para a boa convivência entre pai e filhos; porém, com a sua ausência 
(falecimento), algumas mudanças no relacionamento familiar ocorreram, já que a família tinha seus desentendimentos e eram por ela amenizados.

Quanto aos Sujeitos A e B, estes se relacionam bem, visto que ambos concordam que há entre eles boa comunicação, troca de idéias, respeito e trabalho em equipe. Algo relevante para esta relação se deve ao fato do Sujeito B nunca ter desapontado ou decepcionado o Sujeito A, na visão do segundo. O Sujeito B optou por trabalhar desde a adolescência com o fundador, com a intenção de ajudá-lo na conquista de maior desenvolvimento da empresa. Durante as entrevistas, o Sujeito B com frequência expunha: “(...) meu pai sempre foi rígido comigo, mas isto foi sendo minimizado através da confiança que conquistamos no decorrer dos anos".

Em entrevista, o Sujeito B relatou que formou sua própria família, e com o tempo se tornou sócio da empresa e hoje assume um cargo importante, auxiliando e proporcionando melhorias para a organização, como, por exemplo, trabalho em equipe e incentivo à inovação.

Com relação ao Sujeito D, no início da fundação da empresa, a ele foram depositadas as maiores responsabilidades, pois o Sujeito A necessitava de ajuda para atender a demanda, visto que apresentava poucos funcionários. Segundo o Sujeito D, ele era o filho mais cobrado pelo Sujeito A. No decorrer dos anos, porque não havia por parte do Sujeito D, a comunicação adequada junto ao fundador da empresa, a relação entre os dois foi sendo distanciada.

Os irmãos, normalmente, se interagem quando o momento necessita da presença dos quatro. Embora não haja muito convívio, o afastamento não interfere nas relações, visto que quando se revêem apresentam uma boa convivência. Além disto, os Sujeitos C e D estão sempre em contato com a Color Painéis para ter conhecimento sobre o andamento dos negócios, com o objetivo de se manterem informados, caso haja necessidade de se envolverem em aprofundamentos quanto aos negócios da família.

Feita a análise dos relacionamentos na empresa familiar por meio de entrevistas semiestruturadas e observações, foi possível também identificar as sociedades já formadas e que poderão ser formadas pelos familiares. Da fundação da empresa, até o começo da década de 80, a sociedade envolvia os Sujeitos A e a esposa. Após o Sujeito B adquirir a parte da mãe, formou-se uma nova sociedade (Gráfico 1).

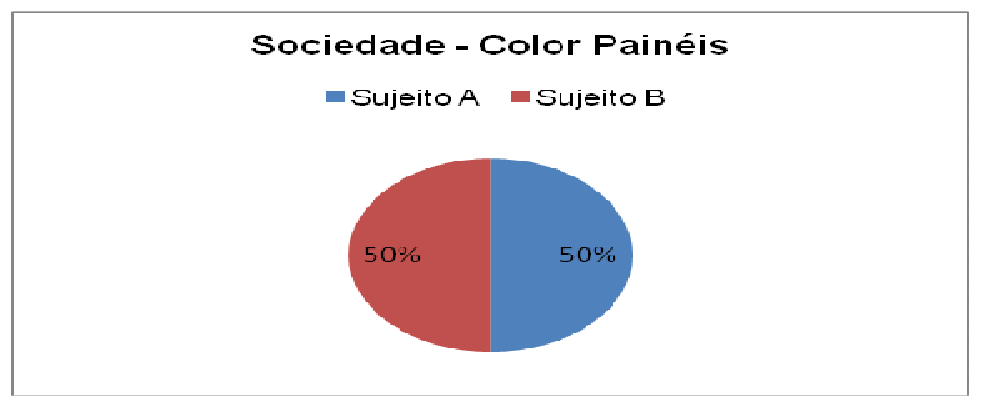

Gráfico 1: Sociedade Color Painéis - SUJEITOS A e B

Fonte: dados da pesquisa (2009) 

EXTERIOR

Apesar de não ocorrer graves problemas entre os irmãos, quando o Sujeito B tornou-se sócio do Sujeito A, com o passar do tempo, os laços familiares não impediram a existência de conflitos na Color Painéis. Os conflitos observados foram: a) falta de entrosamento entre os irmãos; b) diferenças entre idéias, e, c) falta de comunicação.

Se em um determinado momento, o Sujeito A vir a falecer ou decidir repassar a sua parte para os filhos herdeiros sem nenhum planejamento deste momento, percebeu-se por meio das entrevistas que os irmãos tenderão a formar uma nova sociedade com inúmeros sócios, conforme (Gráfico 2).

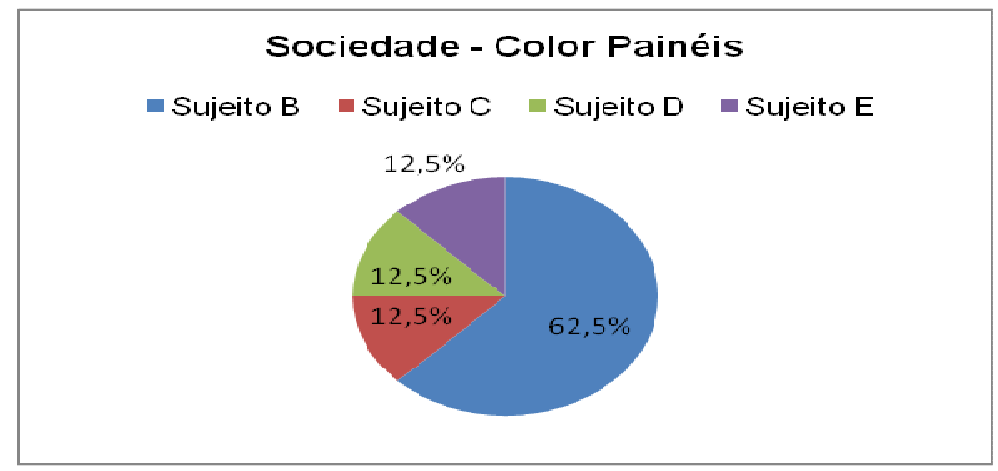

Gráfico 2: Perspectiva futura quanto a Sociedade Color Painéis

Fonte: dados da pesquisa (2009)

Após as entrevistas semi-estruturadas, o Sujeito A mostrou interesse e vê a necessidade em realizar um planejamento do processo sucessório, para assim minimizar as suas dúvidas e os possíveis conflitos entre os filhos. O perfil do sucessor deve ser criativo, eficaz, ter boa comunicação, estar atento às novas tecnologias, e deve prezar os colaboradores, fornecedores e clientes. Além disto, é importante que o sucessor tenha um bom relacionamento com os irmãos e se interesse pelos negócios da empresa.

Portanto, a disputa pelo cargo de direção da empresa, fica em torno dos Sujeitos B, C e $\mathrm{D}$, que mostraram interesse em participar das atividades da empresa. Apesar do Sujeito E não ter mostrado o mesmo interesse, ele acabará tornando-se sócio, e precisará estar presente nas discussões sobre o próximo perfil do sucessor e das tomadas de decisões que irão ocorrer.

\section{CONSIDERAÇÕES FINAIS}

Sobre o desenvolvimento do plano de sucessão para a empresa familiar que se encontra na sua primeira geração, foram identificados certos caminhos que podem facilitar o planejamento do fundador. Chegou-se a conclusão de que, se o fundador dedicar atenção às características individuais dos candidatos a sucessão, em especial quanto ao comportamento de liderança, dedicação e ao investimento feito por cada um dos candidatos à empresa, em termos de idéias e ações, poderá diminuir as chances da sucessão ocorrer de forma insatisfatória.

Visto que a empresa Color Painéis tem sua gestão atual preocupada em criar um ambiente de aprendizagem contínua junto aos seus funcionários, e visa o desenvolvimento de 
produtos inovadores e o atendimento pontual junto aos seus clientes, a compreensão quanto aos valores dos candidatos à sucessão, em relação ao negócio, foi chave para a identificação do melhor perfil de liderança para essa empresa.

Com relação ao plano de sucessão que melhor se alinha às características da empresa investigada, chegou-se a conclusão de que o plano orientado por Oliveira (2006) é o que melhor atende as necessidades do fundador da Color Painéis. Isto porque, dentre as cinco fases existentes no seu plano, existe aquela que permite que o perfil do sucessor seja escolhido conforme a missão, visão, valores e objetivos da empresa, o que não se percebeu no plano de Leone (2005) e Antonialli (1998) e, além disso, por ser um plano claro quanto aos cuidados que devem ser tomados nas diferentes etapas da sucessão.

Para que seja possível a implementação do plano de sucessão de Oliveira (2006), é preciso que haja, em um primeiro momento, o comprometimento de todos os sujeitos envolvidos na organização. Os sujeitos deverão realizar reuniões periódicas para discutir sobre o assunto "sucessão", e assim decidir, juntamente com o Sujeito A, qual será o melhor sucessor para a empresa.

Durante a ampla discussão sobre os resultados que a empresa deve alcançar, e sobre o perfil do sucessor, os sujeitos deverão dar início ao planejamento da sucessão para que não haja um adiamento, mas sim sua realização logo que possível. Além disso, é importante que sejam estabelecidos objetivos e estratégias de sucessão, para que todos, inclusive os funcionários, possam compreender quais serão as situações que se pretende alcançar com o processo sucessório.

Um fato importante que deve ser discutido é o planejamento da distribuição da herança. Mesmo que um sucessor seja escolhido, isto não fará com que a empresa pertença somente a ele, assim, este processo de distribuição de herança deverá ficar bem claro para todos os herdeiros. Após reuniões e debates sobre o quê a Color Painéis deve alcançar, deverá ser discutido qual é o melhor perfil para a empresa. O sucessor será aquele que estará organizando a empresa e repassando aos outros herdeiros, qual a sua real situação. $\mathrm{O}$ futuro sucessor terá que conseguir negociar e administrar os conflitos que sempre existirão, não havendo uma prescrição para extingui-los. Desta forma, o sucessor deverá agir de maneira imparcial, para que os conflitos entre os familiares, não se tornem atritos pessoais.

Assim, foi identificado que o perfil e as características do Sujeito B se adéquam melhor à missão e aos objetivos da Color Painéis, pois ele demonstra ter participação ativa nos negócios da família, e conhece de perto o que acontece no dia-a-dia da empresa. Além disso, possui um perfil de liderança democrática, tendo como habilidades boa comunicação, conseguindo conviver em grupo com bom relacionamento com seus irmãos. Este último é um ponto fundamental, pois a convivência com os demais sujeitos será necessária neste processo.

Desta forma, após a sucessão, deverá ser realizada uma avaliação da sucessão. Este momento será de consolidação do processo sucessório. Para isto, é necessário que o Sujeito A concentre atenção e esforços em observar o sucessor para que ele evolua da maneira mais adequada possível, sempre na busca dos resultados esperados. Com este plano de sucessão, os conflitos entre os herdeiros poderão ser minimizados, visto que deverá haver um 
planejamento do processo sucessório e assim reuniões constantes entre eles, levará ao esclarecimento da situação da empresa de forma igual para todos.

Por este fato, o estudo é relevante para as empresas familiares, principalmente as de pequeno e médio porte, que são a maioria no país, pois mostra um caminho sobre como desenvolver um plano de sucessão para uma empresa familiar que se encontra na sua primeira geração, a partir da administração das diferenças, conflitos específicos deste tipo de empresa, perfis de liderança e criatividade. Com o presente estudo de caso, é possível a realização de novas pesquisas sobre outros tipos de planos de sucessão em empresas familiares, podendo-se realizar uma comparação das características aqui encontradas e resultados, e revelando outras. Além disso, podem-se explorar novos planos de sucessão capazes de facilitar todo o processo sucessório.

\section{REFERÊNCIAS}

ADACHI, Pedro Podboi. Família S.A: gestão de empresa familiar e solução de conflitos. São Paulo: Atlas, 2006.

AMABILE, T. M.; HADLEY, C. N.; KRAMER, S. J. Creativity under the gun. Harvard Business Review, Boston, v. 80, n. 8, p. 52-61, Aug. 2002.

ANDRADE, Maria Margarida de. Introdução à metodologia do trabalho científico. 6.ed. São Paulo: Atlas, 2003.

ANTONIALLI, L. M. Problemas de sucessão e a sobrevivência das empresas familiares. In: Anais do III Seminários em Administração - SEMEAD, 1998, São Paulo. III Seminários em Administração - SEMEAD, 1998. v. 3. p. 1-12.

MAZZILLI, Cláudio Pinho ; CAMPOS, L. J. Análise do Processo Sucessório em Empresas Familiares: um estudo de caso. In: Anais do XXII ENANPAD, 1998, Foz do Iguaçu, PR.

COLOR PAINÉIS. Color Painéis Ltda. Londrina, PR. 2009. Disponível em: <www.color.com.br> Acesso em: 21 ago. 2009.

CONSOLI, M. A. ; MARTINELLI, Dante Pinheiro . Administração de Empresas Familiares. In: Anais do III Seminários em Administração - SEMEAD, 1998, São Paulo. III Seminários em Administração - SEMEAD, 1998.

COSTA, Armando Dalla; LUZ, Adão Eleutério da. Sucessão e sucesso nas empresas familiares: O caso do grupo Pão de Açúcar. $6^{\mathbf{a}}$ Conferência Internacional de Empresas. Minas Gerais: setembro, 2003. 
DACORSO, A. L. R.; RUSSO, R. de Fátima S. M.; SILVA, M. C. M.; ARAÚJO, G. F. de. A Qualidade das Alternativas em Decisões Estratégicas: Um estudo sobre a criatividade e completude em decisões empresariais. RAM - Revista de Administração Mackenzie, v. 11, nº 6, Edição Especial, São Paulo: SP, Nov./dez., 2010.

DAVIS, Keith; NEWSTROM, John W. Comportamento humano no trabalho. São Pioneira: Pioneira, 1992.

DONALDSON, L. Teoria da Contingência Estrutural. In: CLEGG, S. R.; HARDY, C.; NORD, W. R. (Org). Handbook de estudos organizacionais. Cap. 3, v. 1, p. 105-133, São Paulo: Atlas, 1999.

FREIRE, Patrícia de Sá; SOARES, Aline Pereira; NAKAYAMA, Marina Keiko; SPANHOL, Fernando José. Processo de Sucessão em empresa familiar: gestão do conhecimento contornando resistências às mudanças organizacionais. Journal of Information Systems and Technology Management. Vol. 7, № . 3, p. 713-736, 2010.

FREIRE, P. S.; NAKAYAMA, K. M.; SOARES, A.P.; PACHECO, A. S. V.; SPANHOL, F. J. Empresa Tipo Familiar: Processo de Profissionalização para Abertura de Capital (IPO). Revista do CCEI, v. 13, p. 40-52, 2009.

FREITAS, Sidinéia Gomes. Liderança e Poder: um enfoque comunicacional. CAP 6, p.135147. In: MARCHIORI, Marlene (organizadora); vários autores. Faces da cultura e da comunicação organizacional. Editora Difusão, São Caetano do Sul - SP, 2006.

FLORIANI, Oldoni Pedro; RODRIGUES, L. C. Sucessão Empresarial: Processo Sucessório em Empresas Familiares. In: Anais do I EGEPE - Encontro de Estudos sobre Empreendedorismo e Gestão de Pequenas Empresas, 2000, Maringá.

GERSICK, K. E. et al. De geração para geração: ciclos de vida das empresas familiares. São Paulo: Negócio, 1997.

GIL, Antonio Carlos. Como elaborar projetos de pesquisa. 4. ed. São Paulo: Atlas, 2009.

GOFFEE, R. Understanding family businesses: issues for further research. International Journal of Entrepreneurial Behavior \& Research, v. 2, n.1, p.36-48, 1996.

GRZESZCZESZYN, Geverson.; MACHADO, H. P. V. Empreendedorismo e Empresas Familiares: Reflexões sobre a Pesquisa. In: Anais do IX SEMEAD - Seminários em Administração FEA-USP, 2006, São Paulo. Administração no Contexto Internacional, 2006. p. $1-12$.

HERSEY, P.; BLANCHARD, K. H. Psicologia para administradores: a teoria e as técnicas da liderança situacional. Trad. Edwino A. Royer. São Paulo, Editora Pedagógica e Universitária, 1986.

JESUS, Marcos Junio F. de; MACHADO, Hilka Vier P.; JESUS, Anderson F. de. Sucessão familiar: um estudo de caso no setor de turismo. Revista Turismo e Visão e Ação Eletrônica, v. 11, nº 2, p. 142-156, maio/ago. 2009. 
LEONE, Nilda Maria de Clodoaldo Pinto Guerra. Sucessão na empresa familiar: preparando as mudanças para garantir sobrevivência no mercado globalizado. São Paulo: Altas, 2005.

MACHADO, L. A. S. O processo participativo para a melhoria do clima organizacional de uma empresa bancária. Universidade Federal de Santa Catarina. Programa de PósGraduação em Engenharia de Produção. Florianópolis, 2000.

MARTINS, Gilberto de Andrade. Estudo de caso: uma estratégia de pesquisa. São Paulo: Atlas, 2006.

MONTANA, Patrick J.; CHARNOV, Bruce H. Administração. 2 ed. São Paulo: Saraiva, 2006 .

OLIVEIRA, Silvio Luiz de. Tratado de Metodologia Científica: Projetos de pesquisas, TGI, TCC, monografias, dissertações e teses. São Paulo: Pioneira Thomson Learning, 2002.

OLIVEIRA, Djalma de Pinho Rebouças. Empresa familiar: como fortalecer o empreendimento e otimizar o processo sucessório. 2.ed. São Paulo: Atlas, 2006.

PASSOS, Édio, et al. Família, família, negócios a parte: Como fortalecer laços e desatar nós na empresa familiar. 5.ed. São Paulo: Editora Gente, 2006.

QUINN, Robert E.; THOMPSON, Michael P.; FAERMAN, Sue R.; McGRATH, Michael; Competências Gerenciais: Princípios e aplicações. Editora Campus; Rio de Janeiro: Elsevier, 2003.

TRIVIÑOS, Augusto N. S. Introdução à pesquisa em ciências sociais: a pesquisa qualitativa em educação. São Paulo: Atlas, 1987.

WAGNER III, John A.; HOLLENBECK, John R. Comportamento organizacional; tradução Cid Knipel Moreira; revista técnica Laura Zaccarelli. São Paulo: Saraiva, 2006.

WAGNER III, John A. Comportamento organizacional: criando vantagem competitiva. São Paulo: Saraiva, 2002.

WEBER, Max. Burocracia. Os fundamentos da organização burocrática: sociologia da burocracia. Rio de Janeiro: Zahar, 1966. p. 16-27.

YIN, Robert K. Estudo de caso: planejamento e métodos. 2.ed. - Porto Alegre: Bookman, 2001. 